\title{
A Study on Pride and Prejudice from the Perspective of Social Psychology
}

\author{
Loly Yan ${ }^{1}$ Hong Chang ${ }^{2 *}$
}

\begin{abstract}
Pride and Prejudice is one of Jane Austen's early work. The novel mainly describes different love experiences of five daughters in the Bennet's family, and shows the daily life in England's townships from the late 18th to early 19th. Social psychology is usually used as an approach to analyze the psychological activities and behaviors via the analysis of the character's cognitive pattern, family background and social influence. This article employs Social Psychology Theory to analyze the psychological behavior of Darcy and Elizabeth from the perspective of the first meeting, acquaintance, and love. Besides, the possible reasons that results in the facts of misunderstanding also is the concern of this article. Through the related reasons that made the changes in their attitudes, the answer is social psychology is the keynote that leads to the wrong personal interaction and a fine interpersonal communication.
\end{abstract}

Keywords: Social Psychology, Character Analysis, Psychological Behavior

\section{Foreword}

British writer Jane Austen (1775-1817), who has a good family background was born in Hampshire, England. Her education was mainly conducted by her family. She completed her first work Initial Impressions at the age of 21, then renamed Pride and Prejudice. Scarcely do women enjoy the happy life without the dependence on family and marriage, they are nothing but the supplement of the house, with the loss of their true self.

As one of the female writers in the Elizabethan's Age, Jane Austin finished six novels in her whole life. Most of her work concerns the happiness and sadness of the middle class who lived in the countryside. Her works are full of comic description, witty art and deep insight that impressed most readers at that time. In Pride and Prejudice, as the main characters, Elizabeth and Darcy were prejudiced against at the very beginning, with more contacting and understanding, prejudice was replaced by reconciliation and pride was disappeared with the coming of love.

In the field of psychology, Social Psychology is the scientific study of how the thoughts, feelings, and behaviors of individuals are influenced by the actual, imagined, and implied presence of others. Social psychology is the scientific study of the behavior of individuals in their social and cultural setting (Jiang, 2013). Elizabeth's prejudice and Darcy's pride are influenced by the social and cultural environment. Their psychology and behavior are consistent with this theory in the craving of their characteristics and the embodiment of their passions. In sorting out the plot of the story, Austin aims to make it reasonable in the descriptions of the changing attitude in between Elizabeth and Darcy.

${ }^{1}$ School of International Business, Xiamen University Tan Kah Kee College

2 Associate Professor of School of English Language and Culture, Xiamen University Tan Kah Kee College, rainbow@xujc.com*corresponding author 
This study employs Social Psychology to analyze the psychological and behavioral changes between Elizabeth and Darcy. The prejudice comes from Elizabeth. And the causes of prejudice will be discussed in the following. Leon Festinger's theory proposes that inconsistency among beliefs or behaviors causes an uncomfortable psychological tension (i.e., cognitive dissonance), leading people to change one of the inconsistent elements to reduce the dissonance or to add consonant elements to restore consonance (Festinger, 1957). Festinger's theory of cognitive dissonance has been widely recognized for its important and influential concepts in areas of motivation and social psychology. This article mainly explains the phenomenon from two aspects on the basis of the theory: social environment and individual personality. Elizabeth and Darcy come from different social stratum and thus live in different family background. Cognitive dissonance also foreshadows the lives of Darcy and Bingley from the perspective of social and family environments. At the ball where Darcy played for the first time, people compared Mr. Bentley with Darcy. But this comparison was unfair to Darcy. At the end of the article, interpersonal attraction between Darcy and Elizabeth is the focus of the analysis. This paper aims to point out it is the love that break the spell of social prejudice and class segregation. The reconciliation between the lovers can be depicted as the strongest form of interpersonal attraction from Social Psychology.

\section{Characteristic Features of Darcy and Elizabeth}

As the sharpest of the five Bennet sisters, Elizabeth is quick-witted and found disagreeable to some of the novel's other characters because of her sharp tongue. She tends to be prejudiced towards other characters, as shown by her initial reaction to Mr. Darcy, with whom she eventually falls in love. Mr. Darcy is a wealthy gentleman who initially behaves proudly at the first ball. He has a strong sense of pride because of his wealth and social status. He is curious, intelligent, and honest. Like Elizabeth, his negative traits lead him to be negatively perceived by many of the other characters. Over the course of the novel, he grows out of his pride and class-consciousness as he is won over by Elizabeth. At the first ball, Darcy's pride became the fuse of Elizabeth's prejudice against him. With this negative emotion, Elizabeth and Darcy can't understand each other when they get along afterward, causing friction. Darcy's attitude to love is frank and firm, which makes him charmful. After the unfolding of the truth, Elizabeth was overwhelmed with tremendous repents and sorrows. Elizabeth and Darcy show how overcoming one's negative personality traits can lead to a life of fulfillment and happiness.

\section{The Formation of Pride and Prejudice}

In the definition of Social Psychology, attribution is the action of regarding something as being caused by a person or thing. The Attribution theory was introduced by Heider but later it was developed by various psychologists and based on this theory various models were attempted to explain the behavioral processes of attribution. According to Attribution Theory, causes of prejudice are from two aspect: social environment and individual personality. And thus, made the formation of the protagonists' characteristics. The readers may attain the true reasons of pride and prejudice after totally glancing at the paper.

\subsection{Social Factors}

\subsubsection{The Family Background}

In the Pride and Prejudice, Elizabeth was born in a middle-class family and Darcy came from a family with status and property. Elizabeth is clever, resourceful, visionary, selfrespecting, and good at thinking. "He was at the same time haughty, reserved, and fastidious, 
and his manners, though well bred, were not inviting." (Jane Austen, 1813) Darcy believed that his identity was noble and disdain to deal with people of other classes. Darcy's haughtiness leaves Elizabeth a wrong impression. Due to the first bad impression, Elizabeth's prejudice against Darcy appears.

For Darcy, the vulgar behavior of Elizabeth's mother and younger sister makes him think that Elizabeth is the same genre. This is called fundamental attribution error (FAE) in social psychology. FAE is the tendency for people to under-emphasize situational explanations for an individual's observed behavior while over-emphasizing dispositional and personality-based explanations for their behavior ( $\mathrm{Li} \& \mathrm{Chen}, 2006$ ). In other words, people tend to use their subjective emotions to judge the cause of an event. Their family background has created different views on different people and things. These differences also made Elizabeth and Darcy unable to treat fairly each other, resulting in prejudice against each other.

\subsubsection{The Effects of Group Comparison}

At the beginning of the story, people made a comparison between Mr. Bingley and Mr. Darcy. He has a good appearance with gentle demeanor. "Mr. Bingley had soon made himself acquainted with all the principal people in the room." (Jane Austen, 1813) At the ball, Bingley enjoyed dancing and communicating with others, while Darcy refused to dance with others and he was arrogant to others. "What a contrast between him and his friend!" (Jane Austen, 1813) Bingley and Darcy, came to the ball together as good friends, it is quite natural to be the comparison model by the audience. This comparative behavior was called group comparison in Social Psychology. Group comparison benefits the welcomed person, but another one may get unfair treatment.

In daily life, people always compare and criticize others subconsciously. Then they will choose the better thing or people, and belittle another. This is the nature that is hard for people to change. How to reduce inappropriate comparison is still a question.

\subsection{Personal Factors}

Elizabeth is a typical woman with a rebellious spirit. She often used intense words to resist Darcy. She is an independent protagonist with a strong self-esteem, which made her not a follower of Darcy's arrogance. "Vulgar mother and sisters ashamed Elizabeth and her strong self-esteem." (Zhang, 2009). The sense of shame that nurtured form her bosom made Elizabeth dissatisfied with Darcy's arrogance (Pan, 2010). This inferiority complex is an individual's psychological state of tension, which will stimulate the individual to respond. This is why she often resisted Darcy in behavior, and prejudice come into the formation gradually.

Darcy's prejudice stemmed from Elizabeth's mother and sisters, who behaved sordid features. Darcy, the inheritor of the noble family with a purple blood chain. His pride and indifference are the characteristics of the noble stratum who regarded themselves proceed over the middle class, especially the rural ones. Self-centered is part of the characteristics in his blood, arrogance is the sub-producer of his group. However, the appearance of Elizabeth and her actions broke Darcy's identity barrier.

In the sphere of Social Psychology, society and family are the earth for the growth of one's personality. "Compared with the other three marriages in Pride and Prejudice, it is not difficult to find that Elizabeth's charisma is the key to her harvest of love."(An \& Yu, 2012) Elizabeth, with her great merits, is hard to run away from the influence of her original family, falling into the trap of prejudice toward the people from different genres. Arrogance is the label of Darcy, regardless of his loyalty to love and sincere in emotion, in the sphere 
of Social Psychology, the diversity of personality and the opposite family background are the key elements for the formation of one's attitude to life.

\section{Disappearance of Pride and Prejudice}

In Pride and Prejudice, Elizabeth wanted to match Jane and Bingley. As a result, Elizabeth and Darcy had more opportunities to get along. In the process, close interpersonal communication was built on the basis of their initial attraction. Interpersonal attraction is difficult to avoid in the creation. This is the gradual process from the making of prejudice to the smooth ties between the couples.

\subsection{The Definition of Interpersonal Attraction}

In Social Psychology, interpersonal attraction is an individual social psychological phenomenon. Interpersonal attraction as a part of social psychology is the study of the attraction between people which leads to the development of platonic or romantic relationships. It is distinct from perceptions such as physical attractiveness and involves views of what is and what is not considered beautiful or attractive. According to the degree of attraction, interpersonal attraction can be divided into affinity, likes, and love. Darcy and Elizabeth are not an exception in the sphere of interpersonal attraction, they follow the three steps of the procedure and gain their platonic love at last.

\subsubsection{Affinity}

"But no sooner had he made it clear to himself and his friends that she had hardly a good feature in her face, than he began to find it was rendered uncommonly intelligent by the beautiful expression of her dark eyes." (Jane Austen, 1813) One look makes him become amorous with Elizabeth. "He began to wish to know more of her, and as a step towards conversing with her himself, attended to her conversation with others." (Jane Austen, 1813) After he realized his affection for the female protagonist, more focus, attention, and concern all circled around Elizabeth. He scrutinized the treasure he loved most. During the observation, he found her beauty, wisdom, and charm.

When Darcy showed his love, Elizabeth stared, doubted, and was silent. She was shocked by Darcy's love and doubted the love. Due to the first impression, Elizabeth had a hard time accepting an arrogant, indifferent man. The biggest stimulus for Elizabeth was the handwritten letter Darcy sent to her. Darcy ignored all the gaps that might hinder their relationship. Stressful and anxious mood pervades over every vessels and muscle of Elizabeth, made her hard to breathe, not to say open the letter, hesitated for a long time, with great determination and courage, she opened the letter. The contents of the letter are the activator to the gradual change in their ties. This letter impacted deeply on Elizabeth and pushed over walls of prejudice. "She began now to comprehend that he was exactly the man who, in disposition and talents, would most suit her." (Jane Austen, 1813) Elizabeth already had a sense of identity with Darcy. This sense of identity is the first step in interpersonal attraction.

\subsubsection{Likes}

When Darcy confessed his love to Elizabeth, she denied and against voluntarily because of her limited knowing of him and his background. They could not make an agreed decision and reconcile on the trifles and conflicts in the dealing with details. But when Elizabeth read his letter for the second time, she admitted that Darcy understood many of her ideas. Later, Darcy helped the Bennet family solve some problems, and Elizabeth gradually fell in love with Darcy's tolerance. "He was as generous, she doubted not, as the 
most generous of his sex." When Elizabeth learned what Darcy had done for her and her family, the balance in her heart began to lean towards Darcy. Liking to Darcy emerges from Elizabeth's inner bosom. Likes involving other people or things is more emotional than affinity.

\subsubsection{Love}

Love as the intense form of interpersonal attraction is the final emotional expression at the end of story.

After knowing the love for Darcy, Elizabeth had to overcome the twin hurdles from Darcy's family and her own. She tries to defeat against what may hurts her true love. Her rebellious actions against the formidable Lady Catherine, this leads to Darcy's second proposal to Elizabeth. Different from his previous proposal, arrogance, selfishness and extremeness are not the label of Darcy this time. He realized that what Elizabeth wanted was an equal relationship, detached from appearance, wealth and stratum (Zhang, 2006). Therefore, when he learned that Elizabeth had plucked up the courage to negotiate with Lady Catherine for their love, he once again expressed his sincerity to Elizabeth.

At the end of the story, social stratum, family barriers and personal characteristics are not the obstacles barred between the young couples. Darcy devotes himself to this relationship purely and sincerely. Elizabeth, on the same side, cancelled prejudice against Darcy and opens her eyes to the romantic love she's longing for. The God create the world in seven days, not to the melting of rival feelings in between Darcy and Elizabeth, a passage to their true love is a long journey to both sides. Their relationship becomes the model for Austen's definition of a perfect couple and for true love.

Interpersonal attraction starts with the first impression. With the deepening understanding of interaction, the inner beauty of a person is further discovered, and the attraction will become greater and greater. After the first encounterment, Darcy was interested in her performance in social occasions. He walked step by step to the inner world of Elizabeth. Their mutual attraction is based on their own primitive virtues. Elizabeth's wisdom, courage, and independence (Li, 2019). Darcy's knowledge, frankness, and tolerance. Usually, in Social Psychology, personality traits weight heavily in the formation of one's social and personal communication and finally points to successful ties build-ups. Elizabeth's growth and education from childhood to adulthood gave her a valuable outlook on life, allowing her to reap unique love and marriage aside from her original family influence. In character, Darcy and Elizabeth stand on the polar position, but they are similar in some values. To produce interpersonal attraction, the most important thing is to shape the charm of the individual, Darcy and Elizabeth build their own personal charisma on their communication process.

\section{Conclusion}

Social Psychology is a complicated subject because it studies the complex mental state and behavior possessed by human beings. In Pride and Prejudice, the shortcomings and advantages of humanity are reflected at the same time. The phenomenon of prejudice due to the first impression often occurs around us. After years of study, psychologists still fail to find a way to change this nature.

Jane Austen is a writer who is good at describing human nature. In Pride and Prejudice, she uses parody to criticize and belittle human weaknesses such as pride, prejudice, vulgarity, and selfishness. And she praised the flashpoints of self-esteem, sincerity, wisdom, tolerance, and other outstanding human nature. People often fail to see their own shortcomings and often think that what they already know is right and resist the unknown. However, the first 
impression is not necessarily correct, and the experience of life is not always right. Darcy's arrogance becomes a decisive factor trigger for Elizabeth's prejudice against him. Individuals and groups are tightly fastened, cannot independent to each other, their first encounter, acquaintance, and love were changed in psychology. The story of Darcy and Elizabeth is twisty in the process but satisfactory in the end.

Personality psychologic status is greatly influenced by social and personal factors. Elizabeth and Darcy's characteristic defects are rooted in family background and living environment. In Pride and Prejudice, personal characters are thoroughly expressed the notion of social psychology, Elizabeth's prejudice and Darcy's pride lead to the initial unfriendly relationship, personal charisma, another aspect of social psychology, attributes to the establishment of the heroes' intimacy. Through the process of affinity, likes, and love, their emotion for each other surpasses all external factors and becomes platonic love. The road to pursue platonic love is always inflecting and blurry. While Darcy and Elizabeth overcome the psychological adverse effects and obtain a pure emotion. Social Psychology is not a theoretical notion, but also an Answer book to narrate everyone's mental process.

\section{References}

1. An, B. J., \& Yu, H. Y. (2012). Personality and love-Analysis of the charm of the heroine in Pride and Prejudice. Ability and Wisdom, 8, 149.

2. Jiang, Y. (2013). Reflection on the basic issues of social psychology. Science Education Journal, 8, 212-213.

3. Leon, F. (1957). A theory of cognitive dissonance. Palo Alto: Stanford University Press.

4. Li, C., \& Chen, W. Q. (2006). Cultural limitations of fundamental attribution errors. Advances in Psychological Science, 14(6), 938-943.

5. Li, M. (2019). Pride and Prejudice: The feminine traits. Overseas English, 9, 182-183.

6. Pan, Q. J. (2010). Analysis on the psychology of the characters in Pride and Prejudice. Writer Magazine, 22, 63-65.

7. Zhang, L. (2009). Inferiority and compensation-The psychological interpretation of the characters in Pride and Prejudice. Journal of Guangxi Normal University (Philosophy and Social Sciences Edition), 30(2), 96-100.

8. Zhang, Z. (2006). On independence and equality in love and marriage-A comparative study of two marriage in Pride and Prejudice. Wuhan Marine (Journal of Wuhan Marine College), 1(1), 20-25. 